\title{
ESTUDOS CULTURAIS: EMERGÊNCIA, CONCEITOS E APROXIMAÇÕES EM DEBATE ${ }^{1}$
}

\author{
CULTURAL STUDIES: EMERGENCE, CONCEPTS, \\ AND APPROACHES IN DEBATE
}

\author{
ESTUDIOSCULTURALES: EMERGENCIA, \\ CONCEPTOS Y APROXIMACIONESEN DEBATE
}

\begin{abstract}
Daniela de Souza Dias de Souza ${ }^{1}$
Bianca Salazar Guizzo ${ }^{2}$

${ }^{1}$ Universidade Luterana do Brasil (ULBRA), Rio Grande do Sul/RS-Brasil

${ }^{2}$ Universidade Luterana do Brasil (ULBRA), Rio Grande do Sul/RS-Brasil
\end{abstract}

Resumo Este ensaio tem como propósitos principais: 1) apresentar como ocorreu a expansão da perspectiva teórica dos Estudos Culturais, de viés pós-estruturalista, como também exibir o modo como ele se vincula ao campo da educação e como se mostram profícuas algumas problematizaçõesa respeito de diferentes culturas; 2) discutir a potencialidade e a produtividade dareferida perspectiva para investigações desenvolvidas no campo da educação.Para tanto, expõem-se alguns conceitos centrais e potentesutilizados nessa perspectiva, quais sejam: Cultura, Pedagogia Cultural, Identidade, Diferença e Representação. A partir da apresentação e da discussão desses conceitos, argumenta-se que a perspectiva teórica dos Estudos Culturais e sua articulação com a educação convocam-nos a questionamentos e, por conseguinte, a possíveis rupturas, tensionamentos e problematizações de aspectos que se tomavam como fixos, que se representavam como terrenos seguros e confortáveis no campo das teorias e das práticas educacionais.

Palavras-chave: Estudos Culturais; Pedagogia Cultural; Identidade; Diferença; RepreSENTAÇÃO.

\footnotetext{
O presente trabalho foi realizado com apoio da Coordenação de Aperfeiçoamento de Pessoal de Ensino Superior - Brasil (CAPES) - Código de Financiamento 001 e do Conselho Nacional de Desenvolvimento Científico e Tecnológico (CNPQ - Chamada Universal 2018)
} 
Abstract The main purposes of this essay are:1)topresenttheexpansionofthetheoretical perspective of Cultural Studies, of post-structuralist bias, as well as todiscusshow some problematizationsaboutdifferentcultures are productive;2) to present the potential of the theoretical perspective of Cultural Studies for researches in the field of education. Therefore, we present some key concepts in this perspective, which are: Culture, Cultural Pedagogy, Identity, Difference, and Representation. From the presentation and discussion of these concepts, it is important to note that the field of Cultural Studies and its articulation with education creates a split, a tensioning and a problematization of what was taken as certain, of what was represented as safe and comfortable ground in the field of educational theories and practices.

Keywords:Cultural Studies; Cultural Pedagogy; Identity; Difference; Representation.

RESUMEN El presente ensayo tiene como propósitos principales: 1) presentar como ocurrió la expansión de la perspectiva teórica de los Estudios Culturales, de sesgo post-estructuralista, como también presentar el modo como él se vincula al campo de la educación y cómo se presentan potentes algunas problematizaciones al respecto de diferentes culturas; 2) discutir la potencialidad y la productividad de dicha perspectiva para investigaciones desarrolladas en el campo de la educación. Para ello, presentamos algunos conceptos centrales de esta perspectiva, que son: Cultura, Pedagogía Cultural, Identidad, Diferencia y Representación. A partir de lapresentación y discusión de dichos conceptos, destacamos que el campo de losEstudiosCulturales y suarticulacióncom laeducación nos convocan a una ruptura, a una discusión y a um cuestionamiento de aquello que era considerado inamovible y representado como terreno seguro y confortableem el campo de lasteorías y prácticas educativas.

Palabrasclave:EstudiosCulturares; Pedagogía Cultural; Identidad; Diferencia; RePRESENTACIÓN.

\section{INTRODUÇÃo}

Se desejarmos pensar em Estudos Culturais em Educação na América Latina, isso implica, mais uma vez, refletirmos sobre os entendimentos compartilhados acerca desse campo ou desse movimento que cruza fronteiras, inaugura formas diferentes de pensar sobre quase tudo que acreditávamos resolvido, e não se quer estável, definitivo, certo, demarcado, aprisionado em territórios geográficos, disciplinares, teóricos ou temáticos (COSTA; SILVEIRA; SOMMER, 2003, p. 54).

Iniciamos este ensaio com a reflexão proposta pelos/as autores/as citados, pois acreditamos remeter-se ao diálogo sobre um campo teórico recente no palco dos debates sociais, culturais, históricos e educacionais. Também recorremos a essa citação, uma vez que as palavras de Costa, Silveira e Sommer (2003) representamformas diferentes de pensar a 
respeito de quase tudoque acreditávamos estar resolvido, ter solução no campo ao qual nos vinculamos, qual seja, o da Educação.

Nosso principal propósito, por intermédiodeste ensaio, é discorrer e dialogar sobre o campo teórico dos Estudos Culturais, como ocorreu sua expansão, como ele se vincula ao campo da educação e como se apresentam profícuas, nesse campo, algumas discussões acerca da cultura.

Para versar sobre a emergência dos Estudos Culturais, recorremos, mais uma vez, ao autor e às autoras da epígrafe, a fim de compreender o que é o campo dos EstudosCulturais.Esse campo teórico emergiu no cenário pós-guerra, na Inglaterra do século XX, em um movimento de cunho intelectual e político. O mote central de estudo promovido por pesquisadores dessa vertente concentrava esforços para problematizar a cultura, em relação à forma como era até então compreendida, provocando mudanças na forma de entender a cultura e suas reverberações na vida cotidiana. Nas palavras de Costa, Silveira e Sommer (2003, p. 37):

Os Estudos Culturais (EC) vão surgir em meio às movimentações de certos grupos sociais que buscam se apropriar de instrumentais, de ferramentas conceituais, de saberes que emergem de suas leituras do mundo, repudiando aqueles que se interpõem, ao longo dos séculos, aos anseios por uma cultura pautada por oportunidades democráticas, assentada na educação de livre acesso.

Stuart Hall (1932-2014) foi um dos mais proeminentes pesquisadores culturais. Citamos outros pesquisadores/as de referência que buscam problematizar a cultura, dando os contornos ao campo teórico dos Estudos Culturais, a saber: John Storey (1997); Cary Nelson;Paula Treichler, Lawrence Grossberg (1992); Richard Johnson(1986/1987); Tomaz Tadeu Silva (2010).

A emergência dos Estudos Culturais ocorreu, basicamente, em decorrência de dois contextos históricos. O primeiro foi a queda dos impérios coloniais e o colapso doseu domínio, como ocorreu com o império britânico, por exemplo, remexendo com os ideais sociais. O segundo se vinculaaos novos contornos produzidos pelo capitalismo, especialmente após a segunda metade do século XX, com a comunicação de massa, a publicidade, a indústria, criando novas formas de organização, comunicação e relações sociais(COSTA; SILVEIRA; SOMMER, 2003, p. 39).

Os Estudos Culturais se ocupam, especialmente, das discussões que envolvem a cultura e como ela invade os cenários da vida. Dito de outro modo, os Estudos Culturais buscam focalizar suas discussões em questões mais amplas e é justamente aí que:

...parecem residir as principais contribuições que a articulação entre Educação e Estudos Culturais tem possibilitado, na medida em que ela impede que se proceda a uma delimitação definitiva desse campo intermediário, múltiplo ou híbrido de estudos, ou mesmo que se busque centrá-lo obrigatoriamente em uma única e definitiva direção. As análises dos ECE têm se voltado a um anteriormente negligenciado território de pesquisa, que questiona a produtividade da cultura nos processos educativos em curso nas sociedades de hoje (WORTMANN, COSTA e SILVEIRA, 2015, p. 34). 
O conceito de cultura vem sendo reelaborado pelo campo dos EC, e sua conceituação passa a ser entendida em seu aspecto mais amplo, com ênfase naquilo que é tido como popular. Dessa forma, o sentido de cultura como um domínio exclusivo de certos grupos, elitizada, erudita e de tradição estética, passa a abarcar, também, o que é produzido por distintos grupos, inclusive os populares. Nas palavras de Costa, Silveira e Sommer (2003, p. 36):

Cultura transmuta-se de um conceito impregnado de distinção, hierarquia e elitismos segregacionistas para um outro eixo de significados em que se abre um amplo leque de sentidos cambiantes e versáteis. Cultura deixa, gradativamente, de ser domínio exclusivo da erudição, da tradição literária e artística, de padrões estéticos elitizados e passa a contemplar, também, o gosto das multidões. Em sua flexão plural - culturas - é adjetivado, o conceito incorpora novas e diferentes possibilidades de sentido (grifo dos autores).

Sendo assim, cultura passa a ser entendida como um campo de luta e contestação por intermédio do qual se constituem sentidos e sujeitos, que fazem parte de diferentes grupos, cada qual com suas particularidades (HALL, 1997a; SILVA, 2010; MEYER, 2003). Isso significa afirmar que os Estudos Culturais representam um campo teórico que se atém ao estudo das diversas culturas, como a cultura de massa, as culturas juvenis, as culturas indígenas, a cultura surda, bem como, os estudos sobre gênero, mídias, infâncias, classe, raça e etnia.

Por abrangerem a cultura de forma amplificada, os Estudos Culturais se articulam com várias áreas, como as ciências sociais, as ciências naturais, as ciências humanas, a tecnologia, as artes e a educação, como veremosadiante. As pesquisas embasadas nesse campo teórico utilizam metodologias variadas e híbridas, como etnografia, análise de discurso, análises culturais, análise de textos, análises fílmicas, análise de mídias, em que a (re)invenção dos caminhos investigativos é possível e comumente utilizado.

Como foi possível evidenciar, para esse campo teórico, a cultura está presente nas ações cotidianas, nas escolhas, nas formas de ver e entender a realidade, nos modos de se comportar e de agir, na construção de sentido sobre valores sociais, enfim, em cada instância da vida social e individual. Corroborando com os estudos de Stuart Hall (1997a), Costa (2000, p.5) explica:

\footnotetext{
Como a cultura investe, hoje, em cada recanto da vida social, não podendo mais ser concebida com o sentido estrito de acumulação de saberes ou de processo estético, intelectual e espiritual (...). Ela não é um componente subordinado, ela é eminentemente interpelativa, constitutiva das nossas formas de ser, de viver, de compreender e de explicar o mundo.
}

Nesse ponto inicial do diálogo, apresentamos as reflexões acerca do conceito de cultura, que, com as pesquisas dos Estudos Culturais, sofreu uma ruptura em relação a como era compreendida pelo senso comum. Ela pode ser entendida como um conjunto de regras e valores acumulados e transmitidos entre as gerações. Pode ser conceituada, ainda, como alta cultura, ou seja, música, literatura, artes e uma série de comportamentos acessíveis à 
classe alta. Para os Estudos Culturais, tais entendimentos são tensionados e colocados em discussão e, até mesmo, em xeque.

Grossberg,Nelson e Treichler (2011) esclarecem que cultura é - para o referido campo teórico - um conceito complexo e é compreendido como tudo que envolve a vida cotidiana, comportamentos simbólicos, arranjos sociais que resultam em como, por meio da linguagem, as pessoas estabelecem, constroem, organizam, escolhem modos de ver o mundo, de ser, de viver e de se comportar. Destacam, ainda, que esse é um processo bastante complexo, que demanda negociações que envolvem "articulação, conjuntura, hegemonia, ideologia” (GROSSBERG, NELSON e TREICHLER, 2011, p. 29).

Ao considerarmos as proposições emergentes a partir dos Estudos Culturais, não seria coerente continuar a conceber cultura como um campo isolado do restante da vida cotidiana. Além disso, é por intermédio da cultura que compreendemos e explicamos os modelos teóricos do nosso mundo, como define Hall (1997a), é por meio dela que as sociedades estabelecem o que é considerado permitido e o que é negado, o que é aceitável e o que é repelido, o que é certo e o que é errado. Para o autor, a cultura, nas sociedades pós-modernas, ganha um olhar focal. Ele utiliza o termo "centralidade da cultura" para evidenciar como ela penetra em cada instância da vida cotidiana, produzindo e mediando tudo em cada recanto da vida social.

O que os Estudos Culturais nos permitem refletir sobre a cultura é no sentido de considerar tudo que está associado a ela, ou seja, o caráter constitutivo e produtivo da cultura. Isso significa afirmar que toda a atividade humana, a forma de organização social, as relações estabelecidas entre grupos e tudo o que é produzido socialmente, se inserem no contexto da cultura. Portanto, um noticiário, um outdoor, uma música, um filme, um livro, uma revista, um site, uma rede social, por exemplo, não são apenas expressões de uma cultura, mas são produzidos por ela. São dispositivos que se desdobram em práticas, em processos de negociações permeados por hierarquias e relações de poder, produzindo, em certa medida, a forma como as pessoas são, se relacionam, se posicionam e se comportam.

Avançando nas considerações feitas sobre os Estudos Culturais, entendemos que se faz necessária uma breve ampliação, visto que esse campo teórico é marcado por questões polêmicas. Optamos por dialogar a respeito das reflexões propostas por Grossberg (2015), que aprofunda o olhar sobre os Estudos Culturais. O autor se preocupa com a forma como o projeto dos EC está sendo propagada, e de que maneira os pesquisadores do campo podem assumi-lo, considerando toda a sua complexidade.

O projeto dos Estudos Culturais, segundo os estudos de Grossberg (2015), trata da dimensão da cultura sob o viés da contingência, do que é construído e não está posto. $\mathrm{O}$ próprio campo teórico possui esse dinamismo, pois está sempre se transformando e se reformulando para dar conta de respostas condizentes com as mudanças no meio político e cultural. Esse compromisso está veiculado aos questionamentos que se desdobram em reflexões sobre as formas, as práticas e os mecanismos que se constituem - e que continuam em processo dinâmico de reinvenção - permitindo que determinadas práticas, tidas como culturais, se organizem desta ou daquela maneira. 
De modo diferente das teorizações modernas que definem conceitos, evidenciam problemas e buscam soluções fixas e estáveis, os EC se destacam na via contrária, por meio de práticas reflexivas que investigam os contextos, tratando-os como construções mutáveis e temporárias. Além disso, como reitera Grossberg (2015):

\footnotetext{
Os estudos culturais devem transformar-se de acordo com as demandas de seu próprio contexto. Podem-se aproveitar construções e manifestações já existentes do projeto, mas elas devem ser transplantadas "com cuidado considerável" para seu próprio contexto de forças, determinações e contradições (GROSSBERG, 2015, p. 15).
}

As ponderações de Grossberg se ampliam a respeito do referido campo teórico, uma vez que debater sobre EC não se resume em dizer que algo é mais complicado do que parece. Refere-se a estudar a complexidade da realidade, aceitá-la e pensar por meio dela. Nessa direção, significa aprender a rejeitar todo o tipo de reducionismo e universalismo. Isso significa afirmar que os EC possuem caráter "provisório, incerto, aberto e felizmente incompleto" (GROSSBERG, 2015, p. 16).

Grossberg (2015) se debruça a estudar sobre o conceito de conjuntura, haja vista que esse campo se propõe a analisar, discutir, compreender e subsidiar formas de analisar a conjuntura social e política, na direção de compreender as relações culturais e de poder que se constituem.

Nesse sentido, admite que alguns modelos de estudos acadêmicos problematizam pouco seus objetos de estudo, em geral de forma descontextualizada, ou desconexa da conjuntura social, acumulando conhecimentos desprovidos da preocupação de tratar do projeto dos EC. Dessa forma, algumas certezas são lançadas de antemão, sem o compromisso do pesquisador em cogitar estar "errado", compromisso esse que deveria, pelo menos nos Estudos Culturais, caracterizar esse tipo de pesquisa.

Contudo, a preocupação do autor em relação ao que "fazemos" com o projeto dos estudos culturais se expressa na necessidade de expandir os estudos para além do universo acadêmico. Além disso, discute que nem tudo, no universo das análises, pode ser explicado por meio de significação, representação, subjetividade. O confinamento dessas discussões ao meioacadêmico reduz às práticas intelectuais que pouco se dispõem a tratar efetivamente das dimensões complexas que, "na vida real", caracterizam as relações sociais, culturais, de poder.

Os Estudos Culturais possuem um caráter híbrido e multifacetado, sendo possível sua vinculação com a área da educação. A educação se articula com as mais variadas tramas das relações sociais. Torna-se possível reconhecer que a escola não é o único lugar privilegiado de construção de conhecimentos e aprendizagens. A escola é uma entre tantas esferas da vidacotidiana que, envolvida pelas relações sociais e culturais, desenvolve processos educativos. Em função desse entendimento, um conceito potente desse campo é o de Pedagogia Cultural. 
Wortmann, Costa e Silveira (2015, p. 37) argumentam que "deslocamentos dos conceitos de cultura e de pedagogia apontam para percursos em que a primeira vai se transformando em uma dominante na qual a pedagogia assume papel central que se vincula à compreensão de que inúmeras instâncias [...] produzem conhecimentos". Na mesma direção, outro importante autor, Giroux (2013, p. 132), destaca que"[...] outras instâncias culturais também são pedagógicas, também tem uma pedagogia, também ensinam alguma coisa". O mesmo autor ainda argumenta que:

\begin{abstract}
Ao analisar toda a gama dos lugares diversificados e densamente estratificados de aprendizagem, tais como a mídia, a cultura popular, o cinema, a publicidade, as comunicações de massa e as organizações religiosas, entre outras, os Estudos Culturais ampliam nossa compreensão do pedagógico e de seu papel fora da escola como o local tradicional da aprendizagem (GIROUX, 2013, p. 90).
\end{abstract}

Nesse sentido, Steinberg e Kincheloe (2004, p. 14) mencionam que podem ser consideradas áreas pedagógicas todos "aqueles lugares onde o poder é organizado e difundido, incluindo-se bibliotecas, TV, cinemas, jornais, revistas, brinquedos, propagandas, videogames, livros, esportes etc.”.Costa e Andrade (2015, p. 852) contribuem para essa discussão ao afirmarem que os "[...] artefatos da cultura contemporânea provavelmente mais implicados na formação de sujeitos são midiáticos, como textos televisivos, jornalísticos, radiofônicos, publicitários, fotográficos, fílmicos, assim como aqueles das assim chamadas novas mídias, conectadas àworld web wide".

Apesar de reconhecer que os Estudos Culturais e os estudos sobre Educação possuem trajetórias convergentes, conforme nos mostramWortmann, Costa e Silveira (2015, p. 34), a articulação entre ambos permite o estudo de "diferenciadas temáticas, bem como múltiplas ações educativas passaram a permitir que se lide com uma gama ampliada de instituições, práticas, artefatos e produções". Ao se referirem à educação institucionalizada, as autoras abordam, ainda, que a articulação entre educação e os Estudos Culturais permite que esta primeira não fique limitada às fronteiras das diretrizes pedagógicas, dos planejamentos e do ato de ensinar, mas que possibilite a abertura de estudos que contemplem práticas, artefatos e produções que envolvem a cultura nos processos educativos (WORTMANN, COSTA, SILVEIRA, 2015).

As primeiras articulações entre Estudos Culturais eo campo da educação tiveram seu início com pesquisas sobre a educação de adultos, conforme citam Costa, Silveira e Sommer (2003). A aproximação entre esses dois campos está sendo ampliada, com estudos na área do currículo, das metodologias, das relações de poder, assim como em debates sobre as infâncias, juventudes, pedagogias culturais, educação e pós-modernidade e diversas propostas no âmbito das relações sociais na escola e na universidade.

Com o intuito de exemplificar a vinculação do campo dos Estudos Culturais com a educação, mencionaremos brevemente nossas pesquisas, realizadas no âmbito da escola, que vêm problematizando as representações de infâncias contemporâneas acionadas por meio de Projetos Políticos Pedagógicos (PPP) de escolas de educação infantil. Nes- 
ta pesquisa,valemo-nos da articulação entre os Estudos Culturais e a educação, a fim de investigar como artefatos, saberes e práticas estão sendo naturalizados nos documentos escolares, seja pelo embasamento legal ao qual respondem, seja pelo uso frequente desses documentos em práticas que são aparentemente inquestionáveis.

Utilizando os Estudos Culturais em educação, de viés pós-estruturalista, como aporte teórico, o documento escolar PPP passa a ser compreendido como um artefato cultural que, ao descrever e projetar as infâncias, viabiliza condições para que ela seja criada na vertente cultural. Os saberes escolares que são forjados nos documentos escolares nos indicam como os sujeitos infantis estão sendo narrados, pensados e produzidos. Não cabe, na proposta deste ensaio, aprofundar o debate sobre esta pesquisa, mas demonstrar possíveis articulações entre EC e educação.

Os Estudos Culturais em Educação permitem, portanto, repensar a naturalização estabelecida pelas sociedades modernas, no que se referem aos mais variados eventos contemporâneos, possibilitando olhar para a complexidade da educação dos dias atuais. Muitos dos sentidos atribuídos ao fazer pedagógico estão fixados e aceitos como verdades. $\mathrm{O}$ campo teórico dos Estudos Culturais em Educação concede ferramentas para problematizar essas certezas. A esse respeito, Wortmann, Costa e Silveira (2015) destacam que os Estudos Culturais inauguram uma possibilidade de compreender a pedagogia como prática cultural, conforme nomeou Henry Giroux em 1994, uma vez que realiza operações construtivas, moldam sujeitos e fabricam saberes.

Neste ponto do diálogo, consideramos importante fazer referência ao movimento filosófico convencionado como pós-estruturalismo, pois -como realizamos em nossas pesquisas -este também se articula com os Estudos Culturais.Esse foi o nome que se convencionou para explicar o movimento filosófico que iniciou na década de 1960, para marcar posições de divergência sobre o que as ciências exatas e os valores morais haviam estabelecido (WILLIA$\mathrm{MS}, 2013)$. As vertentes estruturalistas tendem a fixar conceitos como verdades absolutas. Ao contrário disto, Williams (2013) explica que para o pós-estruturalismo as verdades construídas não são estáveis, imutáveis e com fronteiras bem definidas, muito ao contrário. Em um sentido mais amplo, o pós-estruturalismo "põe em questão o papel das formas tradicionais de conhecer, no estabelecimento de definições" (WILLIAMS, 2013, p. 15).

$\mathrm{O}$ argumento pós-estruturalista compreende que a linguagem é o meio através do qual atribuímos sentido ao mundo e a nós mesmos. A linguagem sofre um deslocamento significativo, pois, em uma perspectiva estruturalista, estaria a serviço de traduzir em palavras as coisas como elas "verdadeiramente" são. Sob a ótica pós-estruturalista, a linguagem é central na forma como os indivíduos organizam suas relações na sociedade.

Meyer (2000) argumenta que no processo de atribuir sentido às práticas sociais, as oposições binárias são criadas e descritas por teorias estruturalistas como homem/mulher, branco/negro, adulto/criança. A teorização estruturalista se ocupa em descrever como as coisas são, evidenciando as "verdades" sobre elas. Nesse sentido, as pesquisas que assumem essa vertente estudam a palavra em seu significado estável e imutável, as relações sociais considerando aspectos unilaterais e universalistas. Isso significa afirmar que a teorização estruturalista se ocupa em "traduzir" como as coisas são em seu aspecto "essencial". 
A vertente pós-estruturalista coloca em xeque a teorização estruturalista, atribuindo valor central à linguagem. Esta, ao contrário de traduzir a verdade sobre tudo, estabelece os modos pelos quais as pessoas se organizam em sociedade, como estabelecem suas relações e como atribuem sentido ao fazer social. Essas relações são construídas e legitimadas na cultura por intermédio da linguagem.

\section{Que CERTEZas? Quais Verdades? Conceitos Que tensionam nOSSAS FORMaS DE COMPREENDER O MUNDO}

Avançando em relação ao cenário até aqui exposto, entendemos a relevância de destacar alguns conceitos que são caros aos Estudos Culturais, uma vez que são conceitos relevantes para a realização de análises culturais, sejamelas desenvolvidas a partir de pesquisas realizadas no campo escolar ou em outros espaços sociais e culturais a partir dos quais os sujeitos também são ensinados e educados. Além disso, optamos por apresentar os conceitos, pois eles colocam sob suspeita verdades e certezas estabelecidas acerca de como compreendemos nossa realidade.

Além dos conceitos de "Cultura" e de "Pedagogia Cultural" previamente trabalhados, elegemos outros três que se mostram potentes para as discussões e problematizações que vêm sendo propostas no campo dos Estudos Culturais. São eles: identidade, diferença e representação. Antes, porém, julgamos relevante acionar algumas reflexões - mesmo que breves - sobre algumas mudanças ocorridas nas sociedades contemporâneas ocidentais, uma vez que tais mudanças têm possibilitado novas formas de pensar os sujeitos e seus modos de vida em sociedade. É relevante trazer um pequeno recorte dessas mudanças, pois os conceitos de identidade, diferença e representação, passam a ser discutidos sob e a partir de novos olhares.

As sociedades ocidentais do fim do século XX vêm produzindo mudanças estruturais, promovendo diversas rupturas na forma como os sujeitos organizam a vida em sociedade. Uma dessas mudanças aparece nas discussões de Woodward (2008), que menciona a globalização como um fenômeno que abala as antigas estruturas das comunidades nacionais. Segundo a autora, "a globalização envolve uma interação entre fatores econômicos e culturais, causando mudanças nos padrões de produção e consumo, as quais, por sua vez, produzem identidades novas e globalizadas." (WOODWARD, 2008, p. 20).

Quanto aos efeitos da globalização sobre as identidades, Hall (2006, p. 27) argumenta:

[...] a globalização tem, sim, efeito de contestar e deslocar as identidades centradas e "fechadas" de uma cultura nacional. Ela tem um efeito pluralizante sobre as identidades, produzindo uma variedade de possibilidades e novas posições de identificação, e tornando as identidades mais posicionais, mais políticas, mais plurais e diversas; menos fixas, unificadas ou trans-históricas. Entretanto, seu efeito geral permanece contraditório. Algumas identidades gravitam ao redor daquilo que Robins chama de "tradição", tentando recuperar sua pureza anterior e recobrir as unidades e certezas que são sentidas como tendo sido perdidas. Outras aceitam que as identidades estão sujeitas ao plano da história, da 
política, da representação e da diferença e, assim, é improvável que elas sejam outra vez unitárias ou "puras"; e essas, consequentemente, gravitam ao redor daquilo que Robins chama de "tradução" (aspas do autor).

O período pós-guerra inaugurou convergências de culturas e estilos, fragmentando o que, na sociedade moderna, era estável e natural. Observa-se um abalo nos sentidos até então fixos sobre classe, gênero, nacionalidade, etnia, sexualidade e identidade. Se, na sociedade moderna (em meados dos séculos XIII e XIX), os indivíduos se caracterizavam por sólidas e unificadas formas de identidade, a pós-modernidade inaugura a ruptura das noções fixas e essencialistas sobre o sujeito social (HALL, 2006).

As primeiras considerações desta seção apontam para o primeiro conceito que nos propomos a discutir: identidade. No constructo teórico dos Estudos Culturais, a concepção abordada é de que há múltiplas identidades, sejam elas sociais, culturais ou individuais.

Essa concepção aceita que as identidades não são nunca unificadas; que elas são, na modernidade tardia, cada vez mais fragmentadas e fraturadas; que elas não são, nunca, singulares, mas multiplamente construídas ao longo de discursos, práticas e posições que podem se cruzar ou ser antagônicas (HALL, 2000, p. 108).

Hall (2006) aborda a questão da identidade refletindo sobre processos culturais e históricos que fazem deste um dos conceitos fundamentais no campo dos Estudos Culturais. $\mathrm{O}$ autor analisa três momentos históricos que colaboraram para o que se pode chamar de "crise da identidade". O autor explica que o sujeito do período Iluminista era caracterizado por uma identidade fixa, ou seja, o indivíduo nascia com ela. A identidade era considerada essencial, unificada e imutável. A emergência do mundo moderno inaugura outro tipo de subjetividade, o qual o autor nomeou de sujeito sociológico, que ainda possuía uma identidade tida como essencial, mas que poderia ser reconstruída por intermédio das relações dele com outros indivíduos e instituições. Tratava-se de uma concepção interativa do eu. Hall (2006) evidencia que essas identidades (fixa e interativa) estão mudando.

Dessa maneira, ao investigar sobre as mudanças na forma de ver as identidades em diferentes momentos históricos, o autor afirma que a identidade é definida historicamente e não apenas biologicamente. Evidencia que o sujeito pode assumir variadas identidades em momentos distintos da vida, de maneira não mais unificada e coerente, como era concebido em outros momentos históricos.

Trazemos os exemplos de algumas pesquisas sobre infâncias que desenvolvemos ao longo dos últimos anos (GUIZZO, 2018 e SOUZA, 2018), em movimento de articulação entre as ferramentas conceituais e nossos campos de pesquisa, em que não é mais possível pensar em uma infância unificada. A infância é uma forma de nomear as primeiras etapas da vida dos seres humanos, considerada umsistema de significados que são atribuídos ao sujeito infantil, narrando e fixando identidades. A exemplo disso, é aceitável, na cultura urbana contemporânea ocidental, fixar a identidade infantil, atribuindo características que ganharam força na modernidade,como: pureza, imaturidade, alegria, fragilidade, ingenui- 
dade. Contudo, o campo teórico no qual estamos apoiadas auxilia-nos na afirmativa de que essas concepções sobre identidade infantil são constructo social, histórico, cultural, múltiplo, variável e flexível às novas nomeações.

Neste ponto reflexivo, consideramos importante trazer à discussão alguns elementos que se articulam com a produção das identidades, a saber: diferença e linguagem. Não poderíamos marcar o conceito de identidade, sem recorrer à sua construção a partir da diferença - ambas produzidas pelos processos de significação da linguagem.

Recorremos a Silva (2000) para auxiliar-nos a tecer as considerações acerca desses importantes conceitos, uma vez que são ferramentas que nos ajudaram a refletir sobre as infâncias contemporâneas. A identidade, conforme afirma o autor, é marcada pela diferença. Ao definir "quem sou eu", o sujeito infere uma série de negações sobre "quem eu não sou". As identidades são constituídas por complexas cadeias de negações que anunciam "quem o sujeito é" e "quem ele não é". Nesse sentido, "assim como a identidade depende da diferença, a diferença depende da identidade" (SILVA, 2000, p. 73).

Identidade e diferença partilham de uma característica fundamental: a linguagem. "Além de serem interdependentes, identidade e diferença partilham uma importantecaracterística: elas são o resultado de atos de criação linguística" (SILVA, 2000, p. 76).A linguagem neste contexto é compreendida como um sistema de significados que são atribuídos de forma constitutiva, em processos de nomeação, classificação e atribuição de sentido. Sendo assim, é por meio da linguagem e por intermédio de processos históricos e culturais que criamos identidades múltiplas, marcadas pela diferença.

Ancoradas nos pressupostos dos autores mencionados, afirmamos que identidade e diferença são constructos sociais e resultantes de processos simbólicos e discursivos, de negociações que não são harmônicas nem neutras. A esse respeito, Silva (2000) discute sobre o caráter do poder que envolve os sistemas de classificação que narram as identidades. Segundo o autor, é um campo de disputas e hierarquias.

\footnotetext{
Dividir o mundo social entre "nós" e "eles" significa classificar. O processo de classificação é central na vida social. Ele pode ser entendido como um ato de significação pelo qual dividimos e ordenamos o mundo social em grupos, em classes. A identidade e a diferença estão estreitamente relacionadas às formas pelas quais a sociedade produz e utiliza classificações. As classificações são sempre feitas a partir do ponto de vista da identidade. Isto é, as classes nas quais o mundo social é dividido não são simples agrupamentos simétricos. Dividir e classificar significa, neste caso, também hierarquizar. Deter o privilégio de classificar significa também deter o privilégio de atribuir diferentes valores aos grupos assim classificados (SILVA, 2000, p. 75).
}

Avançando e aprofundando o olhar sobre o conceito de identidade, consideramos importante adentrarmos em outro conceito, caro aos Estudos Culturais, e que permite analisar a forma como as identidades são construídas culturalmente. Trata-se do conceito de representação. Na perspectiva teórica cultural contemporânea, identidade e diferença estão relacionadas a sistemas de representação. Na história da filosofia ocidental, a ideia de re- 
presentação estava articulada à busca de formas de tornar o "real"presente - de entendê-lo o mais fielmente possível por meio de sistemas de significação. Entretanto, o pós-estruturalismo reage à ideia clássica de representação e compreende a linguagem e todo o sistema de significação como uma estrutura instável e indeterminada. Nos Estudos Culturais, representação é entendida como um sistema de signos e pode ser expressa por meio de pintura, de fotografia, de filme, de um texto, de uma expressão oral. Ainda nesta perspectiva, o conceito de representação incorpora todas as características de indeterminação, ambiguidade e instabilidade atribuída à linguagem (SILVA, 2000). É preciso entender que a representação engloba sistemas de significados, posicionando os sujeitos de diferentes maneiras no interior das relações culturais.

Resumidamente e apoiadas em Hall (1997b), conceituamos representação como a forma como as sociedades produzem sentido, utilizando a linguagem para fazê-lo. Na perspectiva aqui colocada, representação não significa narrar algo em sua essência, mas construir múltiplos sentidos, criados pela e na cultura, por intermédio da linguagem. Isso significa que não podemos dizer como um objeto ou evento realmente é. Nós criamos sentido para os objetos, sensações, vivências, utilizando a linguagem como veículo comunicativo (HALL, 1997b).

A linguagem permite criar um conjunto de práticas narrativas que produzem significados e "é por meio dos significados produzidos pelas representações que damos sentido à nossa experiência e àquilo que somos" (WOODWARD, 2008, p.17).

A representação, portanto, faz parte de um processo cultural que permite a criação de sistemas classificatórios, posicionando sujeitos e fixando identidades. Os sistemas de representação estabelecem o que é "normal" na sociedade e pode ser entendido como a fixação de identidades aceitáveis. Indicam, ainda, o que é "anormal" ou desviante, fixando a diferença (WOODWARD, 2008).

Na costura entre os conceitos de identidade, diferença e representação, reafirmamos o que foi apresentado por Woodward $(2008$, p. 17) ao destacar que:

A representação, compreendida como um processo cultural, estabelece identidades individuais e coletivas e os sistemas simbólicos nos quais ela se baseia fornecem possíveis respostas às questões: Quem eu sou? O que eu poderia ser? Quem eu quero ser?

Contudo, é possível inferir que as identidades são criações produzidas por sistemas de representação que posicionam os sujeitos, atribuindo uma série de características que são validadas nas relações sociais e culturais. Essas relações não são nada harmônicas nem desprovidas de posicionamento político, como já citado. Estão permeadas por relações de poder, pois quem narra o outro, na maioria das vezes, são os sujeitos representados por identidades hegemônicas, ou seja, aceitas como "naturais" e "normais" em determinados grupos e espaços sociais.

Em uma análise cultural, as ferramentas conceituais apresentadas neste ensaio auxiliam a compreender que as identidades não são inatas ou nascem com os indivíduos. Elas não estão à espera que "alguém" as revele. Vão sendo construídas na medida em que são 
narradas e representadas nas relações sociais. A linguagem produzida por meio da cultura produz formas de ser e viver. Dessa forma, as identidades produzidas evidenciam o que significa ser criança, jovem, idoso, mulher, homem, negro, branco, rico, pobre, refugiado e quais comportamentos são aceitáveis para essas identidades construídas.

\section{CONSIDERaÇões Finais}

Concluímos reconhecendoe destacando que a perspectiva teórica dos Estudos Culturais, de viés pós-estruturalista, e sua articulação com a educação nos convocam a uma ruptura, a um tensionamento e a uma problematização daquilo que se considerava fixo, do que se representava como terreno seguro e confortável no campo das teorias e das práticas educacionais.

Utilizar a perspectiva dos Estudos Culturais em estudos acadêmicos tem possibilitado suspeitar do pensamento hegemônico. Grossberg, Nelson eTreichler(2011, p. 29) explicam que "os Estudos Culturais implicam o estudo de todas as relações entre todos os elementos de uma forma inteira da vida". Utilizar os Estudos Culturais como possibilidade de análise das formas pelas quais as pessoas se constituem na e por intermédio da cultura, significa uma abertura de fronteiras para refletir sobre a sociedade em seus aspectos contingentes, flexíveis e provisórios.

Consideramos importantes as contribuições do campo dos EC para as pesquisas em educação, na medida em que esse campo possibilita analisar e problematizar determinadas representações (que muitas vezes são tomadas como hegemônicas), como construções, invenções, criações, distante das lentes teóricas que afirmam "verdades" sobre todas as coisas.

Encerramos concordando com Williams (2013), ao destacar que somos convidados a promover rupturas no nosso senso seguro de significados e de representações até então tidas como inquestionáveis e confiáveis.

\section{REFERÊNCIAS}

COSTA, Marisa Vorraber. Sujeitos e subjetividades nas tramas da linguagem e da cultura. In: Simpósio sujeitos e subjetividades na contemporaneidade. Texto apresentado no $10^{\circ}$. ENDIPE. Rio de Janeiro: UFRJ, p. 1-15, 29,mai. a $1^{\circ}$.jun. 2000.

COSTA, Marisa Vorraber; ANDRADE, Paula Deporte de. Na confluência entre educação e comunicação, as pedagogias culturais contemporâneas. Perspectiva, v. 33, n. 2, p. 843862, 2015.

COSTA, Marisa Vorraber; SILVEIRA, Rosa Hessel; SOMMER, Luis Henrique. Estudos Culturais, Educação e Pedagogia. Revista Brasileira de Educação, Campinas, v. 23, p.3661, 2003. Quadrienal. Disponível em: http://www.scielo.br/pdf//rbedu/n23/n23a03.pdf. Acesso em: 10 mai. 2018. 
GIROUX, Henry A. Praticando Estudos Culturais nas faculdades de educação. In: SILVA, Tomaz T. da. (Org.). Alienígenas na sala de aula: uma introdução aos Estudos Culturais, 11. ed. Rio de Janeiro: Vozes, 2013, p. 85-103.

GROSSBERG, Lawrence; NELSON, Cary; TREICHLER, Paula A. Estudos Culturais: uma introdução. In: SILVA, Tomaz Tadeu da (Org.). Alienígenas na Sala de Aula: uma introdução aos estudos culturais em educação,9. ed. Petrópolis/RJ: Vozes, 2011,cap. 1, p. 7-37 (Coleção Estudos Culturais em Educação).

. Lawrence; NELSON.Lutando com anjos: os estudos culturais em tempos sombrios. Matrizes, v. 9, n. 2, p. 13-46, 2015. Disponível em:<https://www.revistas.usp.br/ matrizes/article/view/111738. .> Acesso em: 21 abr. 2019.

GUIZZO, Bianca Salazar. Crianças pré-escolares do século XXI:um estudo sobre representações infantis e práticas docentes, 2018, 25s. Projeto de Pesquisa -Universidade Luterana do Brasil, Programa de Pós-Graduação em Educação, Canoas, 2018.

HALL, Stuart. A Centralidade da Cultura: notas sobre as revoluções de nosso tempo. Educação e Realidade.Porto Alegre, v.22, n. 2, p. 15-46, jul./dez. 1997a.

. Stuart. The spectacle of 'other'. In: Hall, S. (Org.). Representation. Cultural Representations and Signifying Practices (Trad. Ricardo Uebel). London, Thousand Oaks, New Delhi: Sage/Open University, 1997b.

. Stuart. Quem precisa de identidade? In: SILVA, Tomaz T. (Org.). Identidade e diferença: a perspectiva dos Estudos Culturais. Petrópolis: Vozes, 2000.

. Stuart. A identidade cultural na pós-modernidade, 11. ed. Rio de Janeiro: DP\&A, 2006. Tradução: Tomaz Tadeu da Silva.

MEYER, Dagmar Elisabeth Estermann. Desfazendo "bagagens culturais": representações em torno de uma cultura teuto-brasileiro-evangélica. In: MEYER, Dagmar Elisabeth Estermann. Identidades traduzidas: cultura e docência teuto-brasileiro-evangélica no Rio Grande do Sul. Santa Cruz do Sul: Edunisc\& Sinodal, 2000,cap. 1, p. 35-83.

. Gênero e Educação: teoria e política. In: LOURO, Guacira Lopes; FELIPE, Jane e GOELLNER, Silvana (Orgs.). Corpo, gênero e sexualidade: um debate contemporâneo na educação. Petrópolis: Vozes, 2003, p. 9-27.

SILVA, Tomaz Tadeu. A produção social da identidade e da diferença. In: SILVA, Tomaz Tadeu. Identidade e diferença. Rio de Janeiro: Vozes, 2000, p. 73-102. 
SILVA, Tomaz Tadeu da. Documentos de identidade: uma introdução às teorias do currículo,3. ed. Belo Horizonte: Autêntica, 2010.

SOUZA, Daniela de Souza Dias de. Representações de infâncias contemporâneas em projetos políticos pedagógicos de escolas de Educação Infantil, 2018, 116s. Dissertação (Mestrado em Educação) - Universidade Luterana do Brasil, Programa de Pós-Graduação em Educação, Canoas, 2018.

STEINBERG, Shirley; KINCHELOE, Joe. Sem segredos: cultura infantil, saturação de informação e infância pós-moderna. In: STEINBERG, Shirley; KINCHELOE, Joe (Org.). Cultura infantil: a construção corporativa da infância, 2. ed. Rio de Janeiro: Civilização Brasileira, 2004, p. 9-52.

WILLIAMS, James. Pós-estruturalismo, 2. ed. Rio de Janeiro: Vozes, 2013. Série pensamento moderno.

WOODWARD, Kathryn. Identidade e diferença: uma introdução teórica e conceitual. In: SILVA, TomazTadeu da (Org.); HALL, Stuart; WOODWARD, Kathryn. Identidade e diferença: a perspectiva dos estudos culturais, 8. ed. Rio de Janeiro: Vozes, 2008,cap. 1, p. 7-69.

WORTMANN, Maria Lucia Castagna; COSTA, Marisa Vorraber; SILVEIRA, Rosa Maria Hessel. Sobre a emergência e a expansão dos Estudos Culturais em educação no Brasil. Educação, Porto Alegre, v. 38, n. 1, p.32-47, 2015,jan./abr. Disponível em: http://revistaseletronicas.pucrs.br/ojs/index.php/faced/article/view/18441.

Acesso em: abr. 2017.

Dados das autoras

Daniela de Souza Dias de Souza

Mestre em Educação pela Universidade Luterana do Brasil. Rio Grande do Sul/RS-Brasil. daniela.souza@ulbra.inf.br

\section{Bianca Salazar Guizzo}

Estágio pós-doutoral pela Universidade de Bolonha-Itália. Doutora em Educação pela Universidade Federal do Rio Grande do Sul/RS-Brasil. Professora na Universidade Luterana do Brasil. Rio Grande do Sul/RS-Brasil.bguizzo_1@hotmail.com

Submetido em: 5-11-2018

Aceito em: 23-4-2019 